\title{
Persepsi Masyarakat Terhadap Fasilitas Dan Pelayanan Angkutan Umum Trans Metro Pekanbaru
}

\author{
Public Perception To Facilities and Public Transportation Services of Trans Metro \\ Pekanbaru
}

\author{
Puji Astuti ${ }^{1}$, Reka Marsela ${ }^{2}$, Mardianto $^{3}$, Thalia Amanda Putri ${ }^{4}$ \\ Program Studi Perencanaan Wilayah dan Kota Fakultas Teknik Universitas Islam Riau \\ Jl. Kaharuddin Nasution No.113 Pekanbaru \\ pujiastutiafrinal@eng.uir.ac.id
}

\begin{abstract}
Abstrak
Permasalahan yang terjadi pada angkutan umum Trans Metro Pekanbaru adalah kedatangan bus selalu tidak tepat waktu dan rute pelayanannya tidak ke semua tempat serta fasilitas halte yang kurang memadai. Tujuan dari penelitian ini yaitu untuk mengetahui persepsi masyarakat terhadap fasilitas dan pelayanan angkutan umum Trans Metro Pekanbaru dan mengidentifikasikan kebijakan pemerintah sebagai pengelola Trans Metro Pekanbaru (TMP). Manfaat dari penelitian ini yaitu agar mengetahui pendapat masyarakat dan kepuasan masyarakat terhadap pelayanan angkutan umum Trans Metro Pekanbaru dalam melayani penumpang. Metode penelitian yang digunakan dalam penelitian ini adalah metode penelitian kualitatif dan dengan pendekatan deduktif. Pendekatan deduktif merupakan penjelasan tentang prinsip-prinsip isi pelajaran, kemudian dijelaskan dalam bentuk penerapannya atau contoh-contohnya dalam situasi tertentu. Responden adalah penumpang Trans Metro Pekanbaru, jumlah responden yang dijadikan sampel penelitian yaitu 115 responden.Hasil dari penelitian ini yaitu tentang ketersediaan Trans Metro Pekanbaru yaitu sebanyak 90 responden menjawab berguna. Alasan masyarakat memilih Trans Metro Pekanbaru yaitu sebanyak 79 responden menjawab tersedia. Akses menuju halte yaitu sebanyak 72 responden menjawab mudah. Tarif ongkos yaitu sebanyak 83 responden menjawab murah. Keamanan dan kenyamanan saat menaiki Trans Metro Pekanbaru serta di halte yaitu sebanyak 55 responden menjawab baik. Pelayanan petugas yaitu sebanyak 70 responden menjawab sopan. Penampilan interior halte dan bus yaitu sebanyak 80 responden menjawab tidak menyenangkan. Kedatangan bus Trans Metro Pekanbaru yaitu sebanyak 71 responden menjawab kurang tepat waktu. Penampilan petugas Trans Metro Pekanbaru yaitu sebanyak 85 responden menjawab rapi. Tentang tempat duduk selalu tersedia saat menaiki bus Trans Metro Pekanbaru yaitu sebanyak 78 responden menjawab tersedia. Total keseluruhan responden yaitu 115 responden. Kesimpulan dari penelitian ini yaitu dalam segi keamanan dan kenyamanannya baik, tarif/ongkosnya terjangkau oleh semua lapisan masyarakat, dari segi negatif yaitu kedatangan bus selalu tidak tepat waktu dan halte kurang memadai. Adapun saran kepada pemerintah yaitu memperbaiki halte yang rusak menjadi halte yang lebih memadai.
\end{abstract}

Kata Kunci : Permaslahan Perkotaan, Persepsi, Masyarakat, Transportasi Publik

\begin{abstract}
The problems that occur on public transport Trans Metro bus Pekanbaru is always imprecise arrival time and route of delivery is not to stop all places and facilities are inadequate. The purpose of this study is to determine public perceptions of the facilities and public transport services Trans Metro Pekanbaru and identify government policies as the manager of Trans Metro Pekanbaru (TMP). The benefits of this research is in order to know the public opinion and people's satisfaction of public transport services in the Trans Metro Pekanbaru airport passengers. The method used in this study is a qualitative research method and deductive approaches. Deductive approach is an explanation of the principles of subject content, then described in terms of implementation or examples in certain situations. Respondents were passengers of Trans Metro Pekanbaru, the number of respondents that the research sample is 115 respondents.Results from this study is about the availability of Trans Metro Pekanbaru as many as 90 respondents answered handy. Communities choose Trans Metro Pekanbaru as many as 79 respondents provided. Access to the bus stop as many as 72 respondents answered easily. Rates / fees as many as 83 respondents answered cost. Safety and comfort while riding the Trans Metro Pekanbaru and at the stop as many as 55 respondents answered either. Ministry officials as many as 70 respondents answered politely. The interior appearance
\end{abstract}


and bus stop as many as 80 respondents answered no fun. Trans Metro bus Pekanbaru arrival of as many as 71 respondents answered less timely. Appearance officer Trans Metro Pekanbaru as many as 85 respondents answered neatly. About seating is always available while riding the Trans Metro bus Pekanbaru as many as 78 respondents provided. The total respondents, 115 respondents. The conclusion of this analysis, in terms of both safety and convenience, tariff / fare is affordable by all levels of society, from the negative aspects of the arrival of a bus always untimely and inadequate shelter. The advice to the government is to improve bus stops are broken into more adequate shelter.

Keywords: Urban Problems, People Perception, Public Transportation

\section{PENDAHULUAN}

\section{Latar Belakang}

Transportasi sangat penting untuk menunjang perkembangan suatu kota apalagi kota-kota besar seperti Kota Pekanbaru yang merupakan kota metropolitan. Pertumbuhan kendaraan bermotor di Kota Pekanbaru sangat tidak sebanding dengan pertumbuhan jaringan jalan, daya tampung ruas jalan terhadap volume lalu-lintas semakin berkurang, dengan demikian permasalahan transportasi jalan akan semakin parah. Apabila tidak segera diambil langkah nyata untuk perbaikannya, maka beberapa tahun ke depan Kota Pekanbaru akan semakin semrawut ditambah lagi dengan kondisi dan pelayanan angkutan umum di Kota Pekanbaru yang tidak baik.

Transportasi yang tertib, lancar, aman, dan nyaman merupakan pilihan yang ditetapkan dalam mengembangkan sistem transportasi perkotaan. Pengembangan transportasi perkotaan juga mengemban misi bahwa angkutan perkotaan haruslah mampu mengurangi kemacetan, mampu mengurangi gangguan lalu-lintas, mampu mempertahankan kualitas lingkungan, serta terjangkau oleh semua lapisan pemakai jasa transportasi. Oleh karena itu sistem jaringan jalan dalam kota harus terintegrasi dengan sistem jaringan jalan antar kota sehingga transportasi dalam kota dapat berfungsi dengan baik dalam melayani aktifitas lokal maupun daerah sekitarnya.

Angkutan umum sebagai bagian dari sistem transportasi perkotaan memiliki peran menunjang mobilisasi masyarakat kota dalam melakukan aktifitas sehari-hari. Angkutan umum juga memegang peranan yang sangat penting dan strategis dalam pengembangan dan pembangunan kota baik pada sektor ekonomi, sektor sosial budaya, maupun sektor pendidikan. Oleh karena itu keberadaan angkutan umum harus ditangani dengan baik dan benar sehingga tidak menimbulkan masalah bagi kehidupan kota.

Angkutan umum adalah angkutan penumpang yang dilakukan dengansistem sewa atau bayar. Termasuk dalam pengertian angkutan umum penumpangadalah angkutan kota (bus, minibus, dan sebagainya), kereta api, angkutan air dan angkutan udara (Warpani , 1990).

Beberapa tahun terakhir ini situasi lalulintas di Kota Pekanbaru semakin padat dan sesak. Pada jam-jam tertentu terjadi kemacetan dibeberapa ruas jalan. Jalan dipenuhi oleh kendaraan pribadi baik roda empat maupun roda dua yang pertumbuhannya tidak sebanding dengan pertambahan luas dan panjang jalan Kota Pekanbaru. Berkaitan dengan hal tersebut Pemko Pekanbaru terlihat terus berbenah dengan mengadakan sarana angkutan massal yakni bus Trans Metro Pekanbaru (TMP) dengan harapan pengguna kendaraan pribadi dapat beralih ke sistem angkutan massal.

\section{Permasalahan}

Sejak beroperasinya bus Trans Metro Pekanbaru, sejumlah kalangan mulai memanfaatkan alat transportasi ini menuju sejumlah tempat yang belum dilayani bus kota atau angkutan oplet. Beberapa permasalahan yang terjadi terkait TMP, yaitu :

1. Kondisi angkutan umum Trans Metro 
Pekanbaru yang kurang layak, serta fasilitas yang disediakan kurang memadai untuk digunakan oleh masyarakat.

2 Tidak semua masyarakat tertarik dalam menggunakan angkutan umum Trans Metro Pekanbaru, dikarenakan pelayanannya kurang baik.

\section{Landasan Teori}

Kebutuhan akan pelayanan angkutan umum penumpang pada daerah perkotaan, biasanya dilayani oleh angkutan kota. Angkutan kota adalah angkutan dari suatu tempat ke tempat lain dalam suatu wilayah kota dengan menggunakan mobil bis umum/atau mobil penumpang umum yang terikat pada trayek yang tetap dan teratur. Menurut Tamin (2000), jaringan rute angkutan umum ditentukan oleh pola tata guna lahan. Adanya perubahan pada perkembangan kota maka diperlukan penyesuaian terhadap rute untuk penumpang demand (permintaan) agar terjangkau oleh pelayanan umum. Angkutan umum penumpang bersifat massal sehingga biaya angkut dapat dibebankan kepada lebih banyak orang atau penumpang yang menyebabkan biaya per penumpang dapat ditekan serendah mungkin. Karena merupakan angkutan massal, perlu ada kesamaan diantara para penumpang, antara lain kesamaan asal dan tujuan. Kesamaan ini dicapai dengan cara pengumpulan di terminal dan atau tempat perhentian. Kesamaan tujuan tidak selalu berarti kesamaan maksud, angkutan umum massal atau masstransit memiliki trayek dan jadwal keberangkatan yang tetap. Pelayanan angkutan umum penumpang akan berjalan dengan baik apabila tercipta keseimbangan antara ketersediaan dan permintaan. Oleh karena itu, Pemerintah perlu turut campur tangan dalam hal ini. (Warpani, 1990).

Standar yang digunakan sebagai tolak ukur kinerja pelayanan angkutan umum dilihat dari segi pengguna jasa berdasarkan studi yang telah dilakukan Bank Dunia (2003) pada kota dan negara berkembang, dapat dilihat pada tabel 1 dan 2 berikut ini :

Tabel 1. Standar Pelayanan Angkutan

\begin{tabular}{|c|c|c|}
\hline \multicolumn{3}{|c|}{ Umum } \\
\hline No & Parameter & Standar \\
\hline 1 & $\begin{array}{l}\text { Waktu antara } \\
\text { (Headway) }\end{array}$ & $1-12$ menit* \\
\hline 2 & $\begin{array}{l}\text { Waktu menunggu: } \\
\text { a. Rata-rata } \\
\text { b. Maksimum }\end{array}$ & $\begin{array}{l}5-10 \text { menit* } \\
10-20 \text { menit* }\end{array}$ \\
\hline 3 & $\begin{array}{l}\text { Faktor muatan } \\
\text { (Load factor) }\end{array}$ & $70 \%$ \\
\hline 4 & Jarak perjalanan & $\begin{array}{l}\text { 230-260 } \\
\text { Km/Kend/hari* }\end{array}$ \\
\hline 5 & $\begin{array}{l}\text { Kapasitas operasi } \\
\text { (Availability) }\end{array}$ & $80-90 \% *$ \\
\hline 6 & $\begin{array}{l}\text { Waktu perjalanan : } \\
\text { a. Rata-rata } \\
\text { b. Maksimum }\end{array}$ & $\begin{array}{l}\text { a. } 1-1,5 \mathrm{jam}^{* *} \\
\text { b. } 2-3 \text { jam** }\end{array}$ \\
\hline 7 & $\begin{array}{l}\text { Kecepatan } \\
\text { perjalanan : } \\
\text { a. Daerah padat } \\
\text { b. Daerah lajur } \\
\text { khusus (Busway) } \\
\text { c. Daerah kurang } \\
\text { padat }\end{array}$ & $\begin{array}{l}\text { a. } 10-12 \\
\mathrm{Km} / \mathrm{jam}^{* *} \\
\text { b. } 15-18 \\
\mathrm{Km} / \mathrm{jam} * * \\
\text { c. } 25 \mathrm{Km} / \mathrm{jam}^{* *}\end{array}$ \\
\hline
\end{tabular}

*World Bank

**Direktorat Jenderal Perhubungan Darat Sumber : Nasution, 2003.

Tabel 2. Standar Ukuran Kinerja Angkutan Umum

\begin{tabular}{|l|l|l|c|}
\hline \multicolumn{2}{|c|}{ Indikator } & Parameter & Standar \\
\hline \multirow{2}{*}{ Efek } & $\begin{array}{l}\text { Kemuda } \\
\text { han } \\
\text { tif }\end{array}$ & $\begin{array}{l}\text { Panjang } \\
\text { trayek yang } \\
\text { dilalui/luas } \\
\text { areal yang } \\
\text { dilayani }\end{array}$ & - \\
\cline { 2 - 4 } & $\begin{array}{l}\text { Kapasi } \\
\text { tas }\end{array}$ & $\begin{array}{l}\text { Jumlah } \\
\text { kendaraan/ } \\
\text { panjang } \\
\text { trayek yang }\end{array}$ & - \\
\hline
\end{tabular}




\begin{tabular}{|c|c|c|c|}
\hline & & $\begin{array}{l}\text { dilalui } \\
\text { (kend/Km) }\end{array}$ & \\
\hline & \multirow[t]{3}{*}{ Kualitas } & $\begin{array}{l}\text { Kecepatan } \\
(\mathrm{Km} / \mathrm{jam})\end{array}$ & $10-12$ \\
\hline & & $\begin{array}{l}\text { Headway } \\
\text { (menit) }\end{array}$ & $\begin{array}{l}10-20 \\
\end{array}$ \\
\hline & & $\begin{array}{l}\text { Waktu } \\
\text { tunggu } \\
\text { penumpang } \\
\text { (menit) }\end{array}$ & $5-10$ \\
\hline \multirow{6}{*}{$\begin{array}{l}\text { Efisi } \\
\text { ensi }\end{array}$} & $\begin{array}{l}\text { Load } \\
\text { factor }\end{array}$ & $\begin{array}{l}\text { Jumlah } \\
\text { penumpang } \\
\text { perkapasitas } \\
\text { duduk/ } \\
\text { satuan } \\
\text { waktu }(\%)\end{array}$ & 70 \\
\hline & \multirow[t]{2}{*}{ Utilisasi } & \multirow{2}{*}{$\begin{array}{l}\text { Jarak } \\
\text { tempuh/hari } \\
\text { (Km/hari) }\end{array}$} & $230-260$ \\
\hline & & & 200 \\
\hline & $\begin{array}{l}\text { Availa } \\
\text { bility }\end{array}$ & $\begin{array}{l}\text { Jumlah bus } \\
\text { beroperasi/ } \\
\text { total bus } \\
\text { yang } \\
\text { dimiliki } \\
\text { trayek (\%) }\end{array}$ & $80-90$ \\
\hline & $\begin{array}{l}\text { Umur } \\
\text { kendara } \\
\text { an }\end{array}$ & $\begin{array}{l}\text { Umur rata- } \\
\text { rata bus } \\
\text { (tahun) }\end{array}$ & 10 \\
\hline & $\begin{array}{l}\text { Kelaya } \\
\text { kan }\end{array}$ & $\begin{array}{l}\text { Pendapatan } \\
\text { DAMRI/ } \\
\text { Biaya } \\
\text { operasi } \\
\text { DAMRI }\end{array}$ & $\begin{array}{l}1,05- \\
1,08\end{array}$ \\
\hline
\end{tabular}

Sumber : World Bank, 2003.

Tujuan utama keberadaan angkutan umum penumpang adalahmenyelenggarakan pelayanan angkutan yang baik dan layak bagi masyarakat.Ukuran pelayanan yang baik adalah pelayanan yang aman, cepat, murah dannyaman. Selain itu, keberadaan angkutan umum penumpang juga membukalapangan kerja. Ditinjau dengan kacamata perlalu-lintasan, keberadaan angkutanumum penumpang mengandung arti pengurangan volume lalu-lintas kendaraanpribadi, hal ini dimungkinkan karena angkutan umum penumpang bersifatangkutan massal sehingga biaya angkut dapat dibebankan kepada lebih banyak orang atau penumpang, banyaknya penumpang menyebabkan biaya penumpangdapat ditekan serendah mungkin. (Warpani, 1990).

Beberapa kriteria ideal angkutan umum (Harries, 1976) :

1. Keandalan: Setiap saat tersedia, kedatangan dan sampai tujuan tepat waktu, waktu total perjalanan singkat, waktu tunggu singkat, sedikit berjalan kaki ke bus, tidak perlu berpindah kendaraan.

2. Kenyamanan; Pelayanan yang sopan, terlindung dari cuaca buruk, mudah naik turun kendaraan, tempat duduk selalu tersedia setiap saat, tidak berdesakan, interior yang menarik, tempat duduk yang enak.

3. Keamanan; Terhindar dari kecelakaan, badan terlindung dari luka benturan, bebas kejahatan.

4. Murah; Ongkos relatif murah terjangkau.

5. Waktu Perjalanan; Waktu didalam kendaraan singkat.

\section{METODOLOGI PENELITIAN}

Penelitian ini bertujuan untuk :

1. Untuk mengetahui persepsi masyarakat terhadap fasilitas dan pelayanan angkutan umum Trans Metro Pekanbaru di Kota Pekanbaru.

2. Mengidentifikasi kebijakan Pemerintah Kota Pekanbaru sebagai pengelola Trans Metro Pekanbaru (TMP).

Metode yang digunakan adalah metode penelitian kualitatif dan dengan pendekatan deduktif.

Sampel yang diambil dalam penelitian ini adalah masyarakat Kota Pekanbaru yang menggunakan angkutan umum Trans Metro Pekanbaru. Perwakilan dari masing- masing masyarakat yaitu penumpang Trans Metro Pekanbaru pada Ruas Jalan Jendral Sudirman adalah 115 responden yang menaiki Trans Metro Pekanbaru. Sedangkan sampel dari pengelola Trans Metro Pekanbaru adalah 2 responden dari instansi terkait yaitu Dinas Perhubungan, komunikasi dan informatika (Dishukominfo) Pekanbaru. 
Penelitian ini dilakukan di Kota Pekanbaru, dengan mengambil lokasi penelitian di Ruas Jalan Jendral Sudirman terutama dikawasan pasar pusat, sebagai bahan studi kasus dalam spesifikasi pengambilan data penelitian.

Titik pengamatan tersebut dipilih karena dikawasan pasar pusat seperti didepan pasar sukaramai ramayana merupakan tempat terbanyak berhentinya angkutan umum Trans Metro Pekanbaru, juga karena Jalan Jendral Sudirman merupakan salah satu jalan yang tersibuk di Kota Pekanbaru.

\section{HASIL DAN PEMBAHASAN}

\section{Kondisi Lalu Lintas}

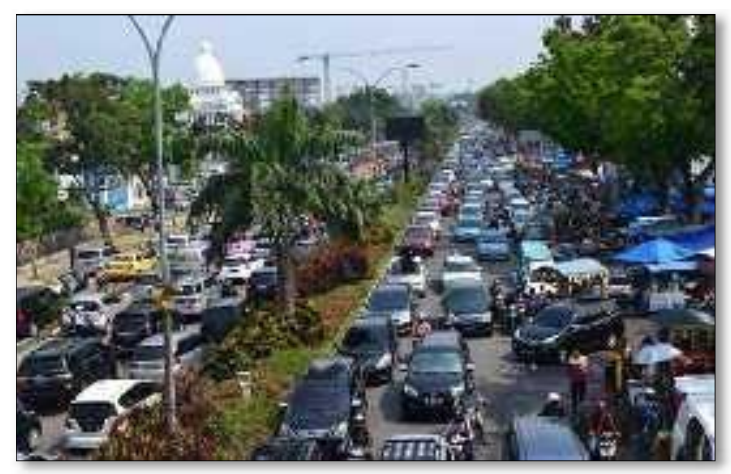

Gambar 1. Kondisi Jalan Jendral

Sudirman pada Jam Sibuk

Sumber: Hasil Survey, 2016

Perkembangan Kota Pekanbaru semakin pesat. Akibatnya, pertumbuhan penduduk pertahunnya pun ikut meningkat. Pertumbuhan penduduk Kota Pekanbaru tergolong sangat tinggi. Penduduk kota bertuah ini sebanyak 1.021 .710 jiwa. Tingginya mobilisasi dan pertumbuhan di Pekanbaru menuju Kota Metropolitan belakangan tahun ini berlangsung sangat cepat. Dinas Kependudukan dan Pencatanan Sipil (Disdukcapil) pada akhir

31 Desember 2013, tercatat jumlah penduduk mencapai 975.304 jiwa namun, baru pada 21 Agustus 2014, jumlah penduduk berkembang menjadi 1.021.710 jiwa. Hal ini tentu saja membuat jumlah transportasi semakin meningkat dan padat, dengan demikian masalah kemacetan pun semakin parah, untuk itu dibutuhkan angkutan umum sebagai solusi dari kemacetan tersebut dan agar masyarakat mau menggunakan angkutan umum daripada angkutan pribadi.

Jalan Jendral Sudirman Pekanbaru termasuk dalam klasifikasi Jalan Perkotaan dan berdasarkan SK Menteri Pekerjaan Umum No:631/KPTS/M/2009, tentang penetapan statusnya sebagai jalan Nasional. Jalan Jendral Sudirman terdiri dari dua jalur, dan terbagi dua arah pergerakan serta dibatasi oleh median jalan. Jalan Jendral Sudirman merupakan jalan arteri primer Kelas II yang memiliki panjang 8.200 meter, lebar jalan 9 meter, lebar pendestrian 2-3 meter, lebar median jalan 2,5-3 meter, dan tinggi median jalan 20-30 cm. Jalur ini berawal dari gerbang Simpang Tiga sebelum Bandara Sultan Syarif Kasim hingga Pelita Pantai.

Jalan Jendral Sudirman adalah Jalan utama, dimana rata-rata pengguna jalan yang ingin melewati jalan mana pun pasti melewati Jalan Jendral Sudirman, selain itu di Jalan Jendral Sudirman ini banyak tempat-tempat perdagangan, perkantoran, yang membuat kondisi kesibukan di jalan ini semakin meningkat. Disepanjang koridor Jalan Jendral Sudirman terdapat beberapa Jalan Lingkungan yang menghubungkan Jalan Jendral Sudirman dengan jalan yang lain, atau sering disebut dengan jalur alternatif.

Dengan banyaknya persimpangan atau titik perpotongan, hal ini mengakibatkan sering terjadi tundaan dikarenakan adanya kendaraan yang berbelok memasuki maupun keluar dari Jalan Lingkungan, sehingga mengakibatkan adanya antrian kendaraan dan menurunnya kecepatan kendaraan. Jalan Jendral Sudirman merupakan koridor utama dan pusat pelayanan lalu-lintas di Kota Pekanbaru. Jalan Jendral Sudirman menjadi penghubung dalam mengalirkan arus lalulintas dari pinggiran kota menuju pusatpusat kota.

Kondisi lalu-lintas disepanjang Ruas Jalan Jendral Sudirman pada sisi kiri dan kanan jalan dipenuhi oleh kawasan perkantoran, kawasan perdagangan dan jasa dan kawasan campuran. Hal ini yang menyebabkan 


\begin{tabular}{|c|c|c|}
\hline No & $\begin{array}{c}\text { Lokasi } \\
\text { Kemacetan }\end{array}$ & $\begin{array}{c}\text { Faktor yang } \\
\text { mempengaruhi } \\
\text { Kemacetan }\end{array}$ \\
\hline 1 & $\begin{array}{l}\text { Plaza } \\
\text { Sukaramai } \\
\text { Ramayana }\end{array}$ & $\begin{array}{l}\text { Adanya aktifitas } \\
\text { perbelanjaan dan } \\
\text { peparkiran kendaraan } \\
\text { umum serta kendaraan } \\
\text { pribadi dibadan jalan. }\end{array}$ \\
\hline 2 & Pasar Buah & $\begin{array}{l}\text { Adanya aktifitas } \\
\text { perbelanjaan dan parkir } \\
\text { mobil pribadi dibadan } \\
\text { jalan serta angkutan } \\
\text { umum yang berhenti } \\
\text { sembarangan menaik- } \\
\text { turunkan penumpang. }\end{array}$ \\
\hline 3 & $\begin{array}{l}\text { Mall } \\
\text { Pekanbaru }\end{array}$ & $\begin{array}{l}\text { Adanya aktifitas dan } \\
\text { pusat perbelanjaan } \\
\text { handhphone serta yang } \\
\text { lainnya. }\end{array}$ \\
\hline 4 & $\begin{array}{l}\text { Plaza } \\
\text { Senapelan }\end{array}$ & $\begin{array}{l}\text { Merupakan pusat } \\
\text { perbelanjaan } \\
\text { handphone, laptop dan } \\
\text { assesoris lainnya. }\end{array}$ \\
\hline 5 & $\begin{array}{l}\text { Hotel } \\
\text { Pangeran }\end{array}$ & $\begin{array}{l}\text { Terdapat aktifitas } \\
\text { sebagai tempat } \\
\text { penginapan, rapat, } \\
\text { mubes, pesta } \\
\text { pernikahan, dan acara } \\
\text { lainnya. }\end{array}$ \\
\hline 6 & $\begin{array}{l}\text { Pizza Hut } \\
\text { Samping hotel } \\
\text { pangeran }\end{array}$ & $\begin{array}{l}\text { Adanya aktifitas berupa } \\
\text { tempat bersantai, makan } \\
\text { dan minum. }\end{array}$ \\
\hline 7 & $\begin{array}{l}\text { Area } \\
\text { pertokoan } \\
\text { penjualan } \\
\text { handphone }\end{array}$ & $\begin{array}{l}\text { Adanya aktifitas depan } \\
\text { pertokoan penjualan } \\
\text { handphone (Modelux, } \\
\text { Vivo, Smartphone) } \\
\text { kemudian diperparah } \\
\text { dengan parkir kendaraan } \\
\text { dibadan jalan sampai } \\
\text { simpang plaza } \\
\text { senapelan. }\end{array}$ \\
\hline 8 & $\begin{array}{l}\text { Vanholanno } \\
\text { Sudirman } \\
\text { samping hotel } \\
\text { pangeran }\end{array}$ & $\begin{array}{l}\text { Terdapat pusat } \\
\text { perbelanjaan dan } \\
\text { aktivitas perdagangan } \\
\text { seperti lemari, kursi } \\
\text { serta kawasan ruas jalan } \\
\text { menuju Fly Over }\end{array}$ \\
\hline
\end{tabular}

bangkitan pergerakan bagi masyarakat yang mengakibatkan terjadinya kemacetan lalu-lintas di Ruas Jalan Jendral Sudirman. Secara rinci dapat dilihat lokasi atau titik puncak kemacetan di Ruas Jalan Jendral Sudirman pada tabel 3 :

Tabel 3. Lokasi Kemacetan Pada
Ruas Jalan Jendral Sudirman

Sumber : Hasil Survey, 2016

\section{Perkembangan Aktifitas Perkotaan}

Dari hasil pengamatan guna lahan yang berkembang sepanjang Ruas jalan Jendral Sudirman, antara lain :

1. Aktivitas perdagangan dan jasa Aktivitasperdagangan dan jasa ditandai dengan adanya pasar pusat seperti Plaza Sukaramai, Pasar Buah, Plaza Senapelan, Mall Pekanbaru, dan pusatperbelanjaan handpone, dan penjualan-penjualan yang lainnya.

2. Aktivitas perkantoran

Aktivitas perkantoran di Jalan Jendral Sudirman yaitu meliputi Bank, seperti Mandiri syariah, Mandiri, BCA, BNI, Bank Nagari, BTN, Bank Ekonomi, dan sebagainya, juga terdapat banyak perkantoran seperti Bappeda Kota, Gubernuran, DPRD Kota, kantor Polresta dan yang lainnya.

3. Aktivitas kesehatan

Aktivitas kesehatan meliputi rumah sakit, seperti Rumah Sakit Awal Bross, RS Syafira dan lain-lain. Selain aktivitas yang disebut diatas, masih banyak lagi aktifitas-aktifitas lain yang tersebar disepanjang Ruas Jalan Jendral Sudirman seperti hotel, pedagangpedagang kaki lima, toko- toko kecil.

Aktifitas Jalan Jendral Sudirman banyak didominasi dengan pusat perdagangan dan jasa, tetapi hal ini tidak didukung dengan pengelolaan sarana transportasi yang baik, salah satunya dengan banyaknya penggunaan kendaraan pribadi daripada angkutan umum, ini membuat pusat-pusat aktifitas seperti dikawasan pasar pusat mengalami kemacetan yang parah terutama di Jalan Jendral Sudirman yang merupakan titik temu semua jenis kendaraan, dari pinggiran kota ke pusat-pusat kota, hal ini akan menganggu lalu-lintas sehingga mengurangi kapasitas jalan tersebut.

\section{Trans Metro Pekanbaru (TMP)}

Trans Metro Pekanbaru atau biasa disebut 
sebagai TMP atau Busway TMP adalah sebuah sistem transportasi bus rapid transit cepat yang terdapat di Kota Pekanbaru. TMP ini telah diresmikan penggunaannya oleh Walikota Pekanbaru, Bapak Drs. H. Herman Abdullah pada Hari Kamis tanggal 18 Juni 2009 Trans Metro Pekanbaru dipusatkan di Terminal AKAP Payung Sekaki yang sekarang sudah beroperasi melalui beberapa koridor di Pekanbaru. Pembentukan Perseroan Terbatas atau PT yang akan mengelola TMP yang berada dibawah naungan PD Pembangunan. Penduduk Kota Pekanbaru saat ini berjumlah lebih kurang 1.000.000 jiwa dan setiap tahunnya bertambah. Saat ini jumlah kendaraan Pribadi di Kota Pekanbaru tidak sebanding dengan jumlah ruas jalan yang ada sehingga menyebabkan kemacetan, pemborosan penggunaan bahan bakar, kebisingan serta tingginya tingkat polusi dan pemandangan yang tidak enak karena lalu-lintas yang semrawut.

Untuk menyikapi masalah tersebut Pemerintah Kota Pekanbaru mengeluarkan kebijakan pelayanan transportasi perkotaan Sarana Angkutan Umum Massal (SAUM) dan diberi nama Trans Metro Pekanbaru dilaksanakan berdasarkan Surat Keputusan Menteri Perhubungan Nomor KP. 111 tahun 2009 dimana Kota Pekanbaru termasuk kota percontohan dibidang transportasi. Pada awalnya, TMP hanya melayani 2 Koridor, namun seiring berjalannya waktu, Trans Metro Pekanbaru telah melayani 8 Koridor yang menjangkau seluruh Kota Pekanbaru dan wilayah aglomerasi terdekat, yakni Kabupaten Kampar.

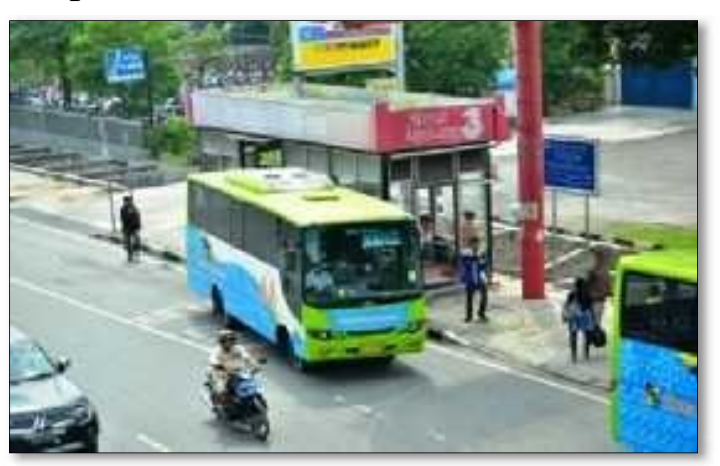

Gambar 2. Bus Trans Metro Pekanbaru

Sumber: Hasil Survey, 2016

Trans Metro Pekanbaru adalah sistem angkutan massal khusus dengan sistem Buy the service di wilayah perkotaan Kota Pekanbaru dengan menggunakan bus pada trayek/jalur yang telah ditetapkan. Motto Trans Metro adalah Aman, Nyaman, Handal dan Terjangkau. Tujuan diadakannya Trans Metro sebagai berikut :

1. Mewujudkan TMP menjadi BLUD (Badan Layanan Umum Daerah dalam rangka kemandirian pengelolaan keuangan dan SDM (Sumber Daya Manusia).

2. Meningkatkan kualitas SDM untuk dapat memberikan pelayanan yang optimal.

3. Meningkatkan pemberdayaan SDM, sarana dan prasarana untuk dapat meningkatkan kepuasan pengguna jasa.

4. Penghematan biaya transportasi.

5. Tersedianya angkutan umum massal yang aman dan nyaman dibidang transportasi.

Perkembangan peminat TMP dari tahun ke tahun mengalami kenaikan, ini berarti antusias masyarakat lebih besar menggunakan angkutan umum massal TMP ini daripada angkutan umum yang lainnya, jika TMP ini dapat diperbaiki terus menerus tidak menutup kemungkinan di Kota Pekanbaru, TMP menjadi angkutan utama yang digunakan masyarakat.

Tabel 4. Perbandingan Jumlah Penumpang Periode 2013-2014

\begin{tabular}{|l|c|c|}
\hline Tahun & $\begin{array}{c}\text { Jumlah } \\
\text { Penumpan } \\
\mathrm{g} \\
\text { (Orang) }\end{array}$ & $\begin{array}{c}\text { Jumlah } \\
\text { Pendapata } \\
\mathrm{n} \\
(\mathrm{Rp})\end{array}$ \\
\hline $\begin{array}{l}\text { Juni- } \\
\text { Desember } \\
2013\end{array}$ & 691.140 & 2.073 .420 .000 \\
\hline $\begin{array}{l}\text { Januari } \\
-\end{array}$ & & 66.601 .034 .00 \\
\hline Agustu & 2.197 .12 & 6 \\
\hline
\end{tabular}




\begin{tabular}{|l|c|l|}
\hline $\begin{array}{l}\text { s } 2014 \\
\text { Jumla } \\
\text { h }\end{array}$ & $\begin{array}{c}2.888 .26 \\
7\end{array}$ & $\begin{array}{l}8.674 .454 .00 \\
0\end{array}$ \\
\hline
\end{tabular}

Sumber : Data BRT TMP 2013 dan

2014

Setelah empat tahun TMP beroperasi, belum ada perubahan yang berarti pada lalu-lintas Kota Pekanbaru. Hal ini disebabkan karena berbagai macam masalah, terutama terhadap kinerja TMP yang bisa dikatakan kurang maksimal, sehingga setidaknya berpengaruh terhadap pelayanan mereka kepada masyarakat Kota Pekanbaru dalam hal angkutan umum dan juga khususnya masyarakat Kota Pekanbaru lebih memilih untuk menggunakan kendaraan pribadi dibandingkan menggunakan jasa transportasi umum dengan alasan faktor kenyamanan dan keselamatan yang lebih terjamin masyarakat Kota Pekanbaru belum juga menunjukan respon yang positif. Jika demikian, tujuan peluncuran TMP untuk penataan kota dan mengurangi kemacetan dapat diprediksi tidak akan tercapai, untuk itu dibutuhkan suatu strategi yang dapat membenahi sistem yang tidak tepat pada pengoperasian TMP sehingga dapat mencapai tujuan awal dari peluncuran TMP

TMP juga mempunyai suatu permasalahan yang besar dimana waktu yang digunakan TMP belum efektif, kotornya fasilitas halte yang ada, kurangnya kursi ruang tunggu supir yang ugal-ugalan sehingga penumpang merasa tidak nyaman saat penumpangnya melebihi kapasitas serta akses yang disediakan oleh TMP juga kurang memenuhi kebutuhan masyarakat Kota Pekanbaru yaitu trayek TMP jauh dari rumah,sekolah tempat tujuan.

Beberapa tahun terakhir ini situasi lalulintas di Kota Pekanbaru semakin padat dan sesak. Pada jam-jam tertentu terjadi kemacetan dibeberapa ruas jalan. Jalan dipenuhi oleh kendaraan pribadi baik roda empat maupun roda dua yang pertumbuhannya tidak sebanding dengan pertambahan luas dan panjang jalan Kota Pekanbaru. Berkaitan dengan hal tersebut Pemko Pekanbaru terlihat terus berbenah dengan mengadakan sarana angkutan masal yakni bus TMP dengan harapan pengguna kendaraan pribadi dapat beralih ke sistem angkutan massal. Seperti yang sering diberitakan oleh harian ini peralihan tersebut tidak semulus yang direncanakan. Ketidakpastian jadwal kedatangan masih menjadi kendala utama dari transportasi ini disamping tidak adanya feeder sebagai sarana angkutan penunjang yang membuat minat masyarakat dalam menggunakan moda transportasi ini sangat rendah.

Bus Trans Metro Pekanbaru menggunakan bahan bakar yang ramah lingkungan sehingga bisa mengurangi tingginya polusi, berkapasitas 33 penumpang duduk dan 32 penumpang berdiri serta beberapa tempat untuk penumpang penyandang cacat yang menggunakan kursi roda dan dilengkapi AC, serta mengutamakan keamanan dan kenyamanan penumpang. Setiap 10 menit sekali bus Trans Metro Pekanbaru berhenti di halte-halte khusus dan bus ini memiliki jadwal dari pukul

06.00 pagi hingga pukul 22.00, dan tidak harus menunggu penumpang penuh, karena sopirnya digaji bulanan tetap, bukan harus mengejar setoran untuk mendapatkan gaji seperti yang terjadi pada bus-bus kota pada umumnya.

Sejak beroperasinya bus Trans Metro, sejumlah kalangan mulai memanfaatkan alat transportasi ini menuju sejumlah tempat yang belum dilayani bus kota atau angkutan oplet. Namun masih ada kelemahan dilapangan, salah satunya kejelasan soal halte transit.

Kelemahan ini diterima PD Pembangunan selaku pengelola lima koridor baru bus Trans Metro. Heri Susanto, Direktur utama PD Pembangunan mengatakan bahwa banyak penumpang dari arah Panam Jalan HR Soebrantas yang ingin ke Pasar Pusat Jalan 
Sudirman, dibebankan biaya tiket dua kaliuntuk sampai

ditujuan.Kelemahannya penumpang ini belum mengetahui dimana posisi halte transit untuk pindah dari koridor satu ke lainnya yang menghubungkan penumpang sampai ke tujuan.

\section{Persepsi Masyarakat terhadap Fasilitas TMP}

Berdasarkan beberapa pertanyaan yang dibuat untuk mengetahui jawaban responden mengenai fasilitas TMP:

1. Akses Menuju Halte TMP dinilai mudah dijangkau oleh masyarakat $(64,35 \%)$.

2. Penampilan Interior Halte dan Bus TMP sangat representaif dan menyenangkan bagi $70,43 \%$ penunpnag.

3. Ketersediaan sarana transportasi massal TMP sangat bermanfaat bagi masyarakat Pekanbaru $(97,39 \%)$.

4. Tempat duduk selalu tersedia saat menaiki TMP $(67,82 \%)$.

\section{Persepsi Masyarakat terhadap Pelayanan TMP}

Berdasarkan kuisioner yang disebarkan kepada 115 penumpang TMP, didapatkan persepsi sebagai berikut :

1. Alasan masyarakat memilih TMP dari pada angkutan lain sebagai sarana transportasinya adalah selalu tersedia saat mereka membutuhkan (96,52\% responden).

2. Tarif atau ongkos TMP sangat terjangkau atau murah, pendapat dari $86,20 \%$ responden

3. Sebesar 90,43\% responden merasakan tingkat keamanan dan kenyamanan saat menaiki TMP.

4. Petugas TMP dalam melayani penumpang berperilaku ramah dan sopan berdasarkan survey pada $71,30 \%$ pengguna.

5. Jadwal kedatangan dan keberangkatan TMP selalu terlambat dan tidak tepat waktu berdasarkan jawaban $62,61 \%$ responden.

6. Penampilan petugas TMP selalu bersih dan rapi menjadi keunggulan tersendiri bagi $92,17 \%$ penumpang.

\section{Kebijakan Pemerintah Kota Pekanbaru dalam Pengelolaan TMP}

Berdasarkan hasil wawancara dengan Dinas Perhubungan Kota Pekanbaru didapatkan hasil tentang pengelolaan TMP agar menjadi angkutan umum yang lebih baik ke depannya yaitu dengan menambah jumlah halte dan bus TMP serta memperbaiki haltehalte yang telah rusak juga jadwal keberangkatan diatur dengan baik agar kedatangan bus dari halte ke halte bisa tepat waktu sehingga membuat masyarakat lebih banyak menggunakan TMP daripada angkutan umum yang lain atau angkutan pribadi.

Kebijakan Pemko Pekanbaru sebagai pengelola TMP yang ingin menjadikan TMP sebagai sarana transportasi yang efektif belum semua terlaksana dengan baik. Efektif dalam arti yaitu sesuatu yang mampu mencapai hasil akhir yang diinginkan dan dianggap akan berhasil atau mencapai yang diinginkan. Sementara, pengelolaan TMP untuk saat ini belum efektif atau belum terlaksana dengan baik karena belum seluruh trayek terlayani dan kedatangan bus selalu tidak tepat waktu.

Untuk itu, saran bagi pengelola TMP agar memperbaiki segala fasilitas TMP seperti halte, dan bus. Sebaiknya perlu penambahan jumlah bus dan halte agar kemudahan dan kelancaran transportasi perkotaan bisa terwujud, serta jadwal keberangkatan yang sebaiknya bisa tepat waktu agar penumpang tidak bosan menunggu lama di halte dan agar bisa menarik masyarakat untuk menggunakan sarana transportasi TMP.

\section{KESIMPULAN DAN SARAN}

\section{Simpulan}

Dari hasil penelitian didapatkan kesimpulan sebagai berikut :

1. Persepsi masyarakat terhadap fasilitas dan pelayanan angkutan umum TMP 
yaitu terjamin keamanan dan kenyamanan, pelayanan petugas yang memadai, terjamin

tingkat keselamatan, dan tarif /ongkosnya terjangkau, serta akses menuju haltenya mudah, kedatangan bus selalu tidak tepat waktu serta fasilitas halte kurang memadai.

2 Kebijakan Pemerintah Kota Pekanbaru sebagai pengelola TMP agar menjadi sarana angkutan umum yang ramai dan dipilih masyarakat maka pengelolaan nya yaitu perlu ditingkatkan seperti kedatangan bus selalu tepat waktu, penambahan fasilitas halte dan bus. Efektivitas sebagai motto TMP belum terpenuhi secara optimal.

\section{Saran}

Kepada Pemerintah Kota Pekanbaru atau Pengelola TMP, sebaiknya melakukan beberapa hal yaitu :

1. Sebaiknya rute melewati semua wilayah berbagai tempat tujuan.

2. Penambahan jumlah halte dan jumlah bus, pada semua koridor yang dilewati oleh TMP.

3. Pengelola TMP meningkatkan fasilitas dan pelayanan yang lebih baik.

4. Masyarakat hendaknya lebih banyak menggunakan sarana transportasi angkutan umum TMP daripada kendaraan pribadi, selain dapat membantu kelancaran transportasi perkotaan di Kota Pekanbaru agar berkurangnya kemacetan, juga membantu APBD di Kota Pekanbaru.

\section{UCAPAN TERIMA KASIH}

Ucapan terima kasih kepada Rektor Universitas Islam Riau, Dekan Fakultas Teknik UIR, dan rekan-rekan pada Prodi Perencanaan Wilayah dan Kota FT UIR yang telah mendukung secara moral dan finansial terlaksananya penelitian ini.

\section{DAFTAR PUSTAKA}

Dinas Perhubungan Komunikasi dan Informatika Kota Pekanbaru. Data Trans Metro Pekanbaru, 2014.

Direktorat Bina Sistem Lalu Lintas dan Angkutan Kota, (1998). Tentang Kebijakan Transportasi Perkotaan Secara Umum, Jakarta.

Direktorat Jenderal Perhubungan Darat, (2002). Tentang Pelayanan Trayek Angkutan Umum, Jakarta.

Direktorat Bina Sistem dan Angkotan Kota, (2008). Tentang Kebijakan Transportasi Perkotaan, Jakarta.

Dinas Badan Perencanaan Pembangunan Kota Pekanbaru. Peta Administrasi Kota Pekanbaru, 2014.

Dinas Badan Pusat Statistik Kota Pekanbaru , Kota Pekanbaru Dalam Angka 2014.

Fahmi Khairul, (2009), Pengembangan Kawasan Sudirman Kota Pekanbaru. Penerbit Universitas Indonesia.

Nasution, H.M., (2003). Manajemen Transportasi, Bandar Lampung.

Nazir, Moh., (2009). Metode Penelitian. Ghalia Indonesia, Jakarta.

Nugroho, (2012). Kebijakan Transportasi Publik Perkotaan, Pekanbaru.

Sugiyono, (2010). Metode Penelitian Kualitatif \& RND. Bandung : Alfabeta.

Tamin, O.Z,. (2000). Perencanaan dan Permodelan Transportasi, Penerbit ITB, Bandung.

Undang-undang No. 22 Tahun 2009 Tentang Lalu-Lintas dan Angkutan Jalan.

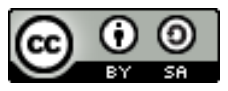

This is an open access article which means that all content is freely available without charge to the user or his/her institution. Jurnal Saintis allows the author(s) to hold the copyright without restriction. The copyright in the text of individual articles (including research articles, opinion articles, and abstracts) is the property of their respective authors distributed under the terms of the Creative Commons Attribution-ShareAlike 4.0 International License(https://creativecommons.org/licenses/by-sa/4.0/) which permits unrestricted use, distribution, and reproduction in any medium. Users are allowed to read, download, copy, distribute, search, or link to full-text articles in this journal without asking by giving appropriate credit, provide a link to the license, and indicate if changes were made. 